\title{
Para o cultivo da saúde: o programa de higiene nas escolas da Paraíba (1913-1942)
}

\author{
Azemar dos Santos Soares Júnior \\ Universidade Federal do Rio Grande do Norte \\ Cláudia Engler Cury \\ Universidade Federal da Paraíba
}

\section{Resumo}

Este artigo tem por objetivo discutir as orientações médicas para a educação da saúde em geral e para a educação da higiene em específico, dirigidas para discentes, docentes e funcionários das escolas públicas e particulares do Estado da Paraíba entre os anos de 1913 a 1942. O trabalho, com base nos artigos das Revistas do Ensino e do Jornal A União orientou-se pelo entendimento teórico-metodológico de Afrânio Peixoło (1925) de que a evolução história da educação da saúde e da higiene revela-se no decurso da história da civilização. Nesse período, o Estado decretou a obrigatoriedade da adoção do "Programa de Educação da Saúde", quando o dever do professor seria velar pelo desenvolvimento natural da criança no que diz respeito à saúde física, mental, social e moral que visou reunir médicos, professores, alunos e familiares

246 em defesa da formação de um cidadão saudável, forte, vigoroso e comprometido com sua nação.

Palavras-chave: Programa de educação da saúde. Educação da saúde. Higiene.

\section{Health culture: hygiene program in schools of Paraiba State}

\section{(1913-1942)}

\section{Abstract}

This article aims to discuss the medical guidelines for health education in general and hygiene education in specific, addressed to students, teachers and employees of the public and private schools of the State of Paraíba between the years of 1913 to 1942. The work, based on the articles of the Journals of Education and the newspaper A União was guided by the theoretical-methodological understanding of Afrânio Peixoto (1925) in which the evolution history of health education and hygiene is revealed in the course of the history of civilization. During this period, the state enacted the mandatory adoption of the "Health Education Program" where the teacher's duty would ensure the natural development of children under the points of view of physical, mental, social and moral health aimed at bringing together doctors, teachers, students and family in defense of the formation of a healthy citizen, strong, vigorous and committed to his nation.

Keywords: Health education program. Health education. Hygiene. 


\section{Para el cultivo de la salud: el programa de salud en las escuelas de el estado de Paraíba (1913-1942)}

\section{Resumen}

Este artículo tiene como objetivo discutir las pautas médicas para la educación sanitaria en general y para la educación de la higiene, en particular, dirigidos a estudiantes, maestros y empleados de escuelas públicas y privadas en el estado de Paraiba entre los años 1913 a 1942. El trabajo, con base en los artículos de la Revista de la Educación y del diario A União fue guiado por el conocimiento teórico y metodológico de Peixoto (1925) en el que la historia de la evolución de la educación sanitaria e higiene se revela en el curso de la historia de la civilización. Durante este período, el estado promulgó la adopción obligatoria del "Programa de Educación para la Salud", cuando el deber del maestro garantizaría el desarrollo natural del niño en relación con la salud física, mental, social y moral que tiene por objeto reunir a médicos, maestros, los estudiantes y sus familias en defensa de la formación de un ciudadano sano, fuerte, vigoroso y comprometido con su nación.

Palabras clave: Programa de educación para la salud. Educación para la salud. Higiene.

\section{Introdução}

Imaginemos um início de manhã ensolarada. Professores e professoras agitados finalizavam os preparativos para exposição dos trabalhos a serem apresentados durante a III Semana Pedagógica, realizada no ano de 1936. Nessa ocasião, foram exibidos diversos jogos educativos criados pelos professores dos diferentes estabelecimentos de ensino da Paraíba. Jogos desenvolvidos para as matérias e apresentados enquanto formas de educar e modelar os sentidos da criança no ensino primário. A iniciativa promovida pelo Departamento de Educação do estado da Paraíba visava partilhar os saberes produzidos na tarefa de educar, bem como tomar ciência das atividades pedagógicas, desenvolvidas nas escolas.

Os trabalhos apresentados versavam sobre Linguagem e Aritmética, História do Brasil e da Paraíba, Ciências e Higiene. Durante a preparação, cada escola recebeu um espaço físico para expor os seus trabalhos obedecendo à seguinte ordem: a Escola de Applicação, apresentando os trabalhos 
desenvolvidos pela professora Azeneth Carvalho Toledo, Beatriz Correia, Laura Campello e Severina Barreto; o Grupo Escolar Antônio Pessoa com as professoras Guiomar Leal Soares, Elvira Pereira Assunpção, Eunice Lyra e Laura de Sousa Cantalice; o Grupo Escolar Epitácio Pessoa representado pela Maria Camerina Bezerra Cavalcanti; o Grupo Escolar Dr. Thomaz Mindello com Severina Carvalho, Avany Fonseca e Severina Carvalho, e os Grupos Escolares Pedro II, Isabel Maria das Neves e Santo Antônio, as Escolas Ruy Barbosa e Almeida Barreto, além da Escola Parochial Nossa Senhora de Lourdes.

Apesar de as apresentações contemplarem as diversas matérias, trataremos aqui de discutir as orientações médicas para a educação da saúde em geral e para a educação da higiene em específico, dirigidas para discentes, docentes e funcionários das escolas públicas e particulares do Estado da Paraíba no período de 1913 e 1942. Nesse sentido, problematizamos os artigos publicados pela Revista do Ensino' e pelo jornal A União² acerca dos mecanismos debatidos sobre a higiene das escolas e dos corpos que ali habitavam e dos encontros pedagógicos sobre a matéria de Higiene, e, orientados para normalização dos corpos infantis ${ }^{3}$.

\section{A educação da saúde e o combate à "moleza de lesma"}

"Apellando para o patriotismo do actual presidente animo-me a lembrar s. exc. que se torna preciso o ensino de hygiene nas escolas públicas do Estado e uma rigorosa inspecção sanitária das mesmas". Assim alertava Flávio Maroja através dos escritos publicados pel'A União em 24 de novembro de 1913. A notícia chamava a atenção para a necessidade de implantar a matéria de Higiene nas escolas da Paraíba como forma de atingir bons níveis de civilidade. Fazia-se necessário "[...] instituir entre nós o serviço sanitário escolar em suas múltiplas modalidades [...]" (MAROJA, 24 nov. 1913); especialmente, num momento em que a população paraibana vivenciava um considerável crescimento populacional. A principal preocupação dos médicos era com a proliferação de doenças contagiosas dentro das escolas, fazendo com que medidas de profilaxia fossem postas em prática determinando ser obrigação "[...] de todo pessoal, qualquer que seja a função a que se destina, ao exame médico rigoroso antes de ser lavrado o acto de sua nomeação ou matriculado o alumno [...]" (MAROJA, 1913, p. 9). A proposta era exatamente proibir que 
os candidatos a funcionário público, portador de quaisquer moléstias, assumissem qualquer função dentro das instituições protetoras da infância; bem como os alunos que só podiam ser matriculados, apresentando atestado de saúde física e mental.

Na segunda década do século XX, visualizamos por meio das chamadas públicas para a matrícula, a necessidade de apresentar o atestado médico no ato da inscrição. Isso, porém, não era suficiente, visło que os candidatos ainda precisavam passar pela inspeção médica da escola. $\bigcirc$ Colégio Nossa Senhora das Neves exigia claramente documentos comprovando "[...] certidão de idade, attestado médico provando ter sido vacinada e não sofrer de moléstia infecto contagiosa [...]" (COLLEGIO NOSSA SENHORA DAS NEVES, 1927, p. 12); o Colégio Pio X, alegando haver passado pela reforma do ensino, exigia para o ingresso ao curso primário atestado médico e a avaliação do médico escolar; já a Escola Normal publicou, no dia 22 de janeiro de 1913, mediante a fala de seu secretário, José Eugênio Lins de Albuquerque, o convite para "[...] quem possa interessar que a matrícula para quem pretende cursar a mesma escola estará aberta de primeiro a último dia de fevereiro vindouro [...]" (DIRECTORIA DE HYGIENE, 1913, s/p). Um dos pré-requisitos para a investidura na escola era o "[...] ettestado médico provando estar vaccinado ou não ter sido affectado de varíola, e não sofrer de moléstia contagiosa ou incompatível com o magistério [...]" (DIRECTORIA DE HYGIENE, 1913, s/p).

$\bigcirc$ atestado médico exigido nas escolas públicas para efetivação da matrícula deveria conter dados do aluno e a rubrica do médico responsável, confirmando o fato de a criança não possuir doença contagiosa e estar com a vacinação em dia. O Instituto Pedagógico, localizado na cidade de Campina Grande, rigorosamente cobrava a documentação médica. Tornou-se conhecida também por prestar "[...] relevantes serviços à causa da instrução do interior do Estado é responsável por criar hábitos higiênicos àquella cidade [...]" (VIDA ESCOLAR, 1926, p. 5). Na publicação de Flávio Maroja, o Instituto Pedagógico, dirigido, à época, pelo tenente Alfredo Dantas, possuía a missão de não abandonar Campina Grande à falta de educação e civilidade. Caso um dia a escola viesse a fechar suas portas "[...] privaria aquella importante cidade, de um educandário que pela sua disciplina e aplicação as lettras, vem se impondo a admiração de todo o parahybano" (VIDA ESCOLAR, 1926, p. 5). $\bigcirc$ sanitarista fazia questão de ressaltar que a escola era um modelo a ser seguido devido a seu compromisso com a educação da saúde, salientando, 
ainda, que a referida instituição estava preparada para receber a visita de políticos considerados ilustres, a exemplo da visita feita pelo senador Washington Luiz que "[...] testemunhou a abnegação e a capacidade de trabalho do seu venerado director e o modelo de higiene escolar adotado" (VIDA ESCOLAR, 1926, p. 51.

Nesse sentido, essas escolas só poderiam entrar para o rol daquelas consideradas higiênicas se, no desenvolvimento pleno de sua organização, compreendesse:

I - A inspecção médica dos collégios no ponto de vista: a) da profilaxia das moléstias infecto contagiosas; b) do exame e attestado de um limitado numero de alumnos ausentes da escola por motivo de moléstias; c) do exame de todas as crianças inaptas para os trabalhos escolares comuns ou para o exercício físico; da inspecção dos alumnos com moléstias da visão, audição, obtusos, defeituosos e epiléticos.

II - Exame médico dos professores das escolas e outros funcionários das escolas.

III - Fiscalização sanitária das escolas.

IV - Preparo instructivo dos professores em hygiene (REFORMA DO ENSINO, 1918, p. 131.

Reafirmamos: os médicos consideravam o atestado médico ser o bilhete de entrada para escola, tanto para alunos quanto para professores e funcionários. Ao analisarmos a documentação do antigo Instituto Pedagógico, deparamo-nos com o atestado médico de uma antiga funcionária. Vamos ouvi-o: "[...] Attesto que a Sra. Rachel Margarida da Silva Soares não soffre de moléstia infecto contagiosa, doenças da visão e já foi vacinada contra varíola. Campina Grande, 14 de novembro de 1939". Era o que assegurava - Dr. Elpídio de Almeida, médico que divulgava os ensinamentos do famoso Oswaldo Cruz: "Só tem varíola quem quer!". Assim, junto a seus atestados vinham os seguintes dizeres: "[...] Toda pessôa deve ser vaccinada dentro do primeiro anno do nascimento e revaccinada de sete em sete annos [... $]^{\prime \prime}$ (VACCINA ESCOLAR, 1939, s/p), como defendia a Campanha liderada pela Directoria de Saúde Pública do Estado, conforme apresentamos na(s) imagem(ns) 1 a seguir: 


\section{Imagem I}

Ficha de vacinação antivariólica (frente e verso)
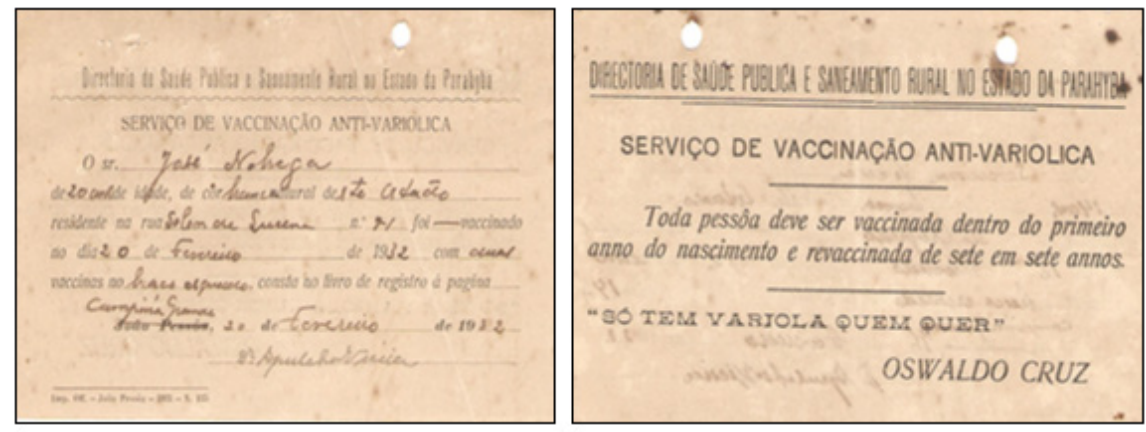

Fonte | Arquivo do Instituto Pedagógico Alfredo Dantas (1932)

Essa documentação deveria ser apresentada no ato da posse dos professores, bem como a diretoria da escola para qual o professor fosse designado. Ressaltamos que, devido à escassez de médicos para o atendimento público, as escolas precisavam possuir seu próprio funcionário da saúde. Em prestação de conta das despesas do Ginásio Alfredo Dantas ${ }^{4}$ em 20 de junho 1943, o diretor escolar alegou gastar mil e quinhentos cruzeiros mensais com o pessoal médico, na intenção de suprir a carência.

A preocupação enfática com os atestados médicos representou uma forte precaução contra moléstias ou defeitos orgânicos da criança. De acordo com Pierre Silva e Kátia Cavalcanti (2004), os cuidados com os corpos infantis recaíam sobre os hábitos corporais e refletiam na organização social. Tratavam-se de normas disciplinares consideradas como parte de um projeto de extensão pedagógica do projeto civilizador burguês que contribuía para instalar nos indivíduos comportamentos auto-disciplinados e moderação nas emoções por meio de gestos estilizados e temporalizados.

Os cuidados com os corpos infantis pareciam ser dobrados. Pensava-se no corpo em todas as suas dimensões. Começava-se pelos cuidados com a higiene intelectual até chegar à higiene no corpo. Numa conferência realizada na III Semana Médica, em 1928, o Dr. Oscar Oliveira de Castro apresentou sua tese sobre os cuidados com a higiene intelectual, visto que se trata de um "[...] trabalho que produz um desgaste de energias e essa perda chega, às vezes, a exceder o quanto licitamente salutar [...]" (CASTRO, 1928, p. 17). 
Afirmava, fervorosamente, que as atividades mentais estão intimamente ligadas, não apenas ao fator individual, mas também ao cósmico, às influências das estações, do clima, da luz e temperatura. Assim, os funcionários - professores, médicos e inspetores - deviam dedicar especial atenção à fadiga escolar, suas causas e efeitos, e, sobretudo, à influência que ela exerce sobre o meio; especialmente num estado onde o calor é companhia diária.

médico chamou a atenção para os cuidados com a higiene da infância ${ }^{5}$, preocupação recorrente entre os médicos e sociólogos da época, pois a infância era vista "[...] como a phase da vida de maior fragilidade, é da mesma sorte aquella em que a hygiene tem maior força conservadora [...]" (DOENTEUR, 1928, p. 17). Alegava, ainda, que, se a criança sofre dos males causados pela falta de higiene, a culpa deveria ser atribuída, totalmente, à família; assim sendo, as crianças seriam "[...] vítimas irresponsáveis e que soffre logo as consequências dos menores desvios hygiênicos, pela delicadeza e fragilidade do seu organismo em formação [...]" (DOENTEUR, 1928, p. 17). Reforçava a necessidade dos cuidados com os prédios escolares que deveriam ser "[...] amplos, bem arejados, limpos, alternativas racionais de horas de trabalho e horas de descanso, jogos escolares, bôa educação da attenção, 252 horário de refeições etc". Os prédios considerados higiênicos contribuiriam para evitar o cansaço mental, bem como impediriam que os alunos se afastassem dos princípios "bôahygiene". A criança precisava ser colocada em boas condições propícias para fazer nascer o desejo de possuir um corpo saudável e higiênico por meio dos métodos, técnicas e atividades fisiológicas e patológicas. Um prédio que não assegurava os princípios da boa higiene significava o surgimento de malefícios como a fadiga cerebral e a saúde.

Oscar Oliveira de Castro afirmou, ainda, que a fadiga era um poderoso inimigo da educação da saúde, pois, embora seja uma característica comum aos corpos de homens e mulheres,

[...] representa uma diminuição do poder funccional dos órgãos, provocado por um excesso de trabalho e acompanhado de uma sensação característica de mal estar; que tanto pode ser física (cansaço do corpo) como mental (aquella occasionada pelo trabalho mental) (DOENTEUR, 1928, p. 17).

Embora fosse uma característica natural aos alunos que passavam horas em plena atividade física e intelectual, a fadiga exigia cuidados, visto 
que "[...] produzia substâncias tóxicas que se disseminam pelo organismo [...]" (PEIXOTO, 1925, p. 369). Entre as causas mais recorrentes da fadiga dentro das escolas, estava o excesso de matérias do ensino, horários de recreio, reparação do trabalho, leituras inadequadas, posturas físicas incorretas, prédios e mobília inadequada, a elevação da temperatura. Concernente a esse último item, o médico reservou boa parte de seu discurso. Bradou que o calor é capaz de produzir grandes modificações no organismo com certo grau de intensidade: "[...] a ação constante e prolongada do calor há uma diminuição dos movimentos respiratórios; a digestão soffre effeito depressivo, há uma diminuição da funcção urinária e a nutrição é deprimida pelo calor excessivo [...]" (DOENTEUR, 1928, p. 17).

Vários médicos se dedicaram ao estudo dos efeitos da fadiga nas escolas. Ao citar Francis Galton, Afrânio Peixoto afirmou que a fadiga prova-se e mede-se por suas consequências sobre todas as funções do corpo: circulação, respiração, trocas nutritivas, força muscular, funções motoras, sensitivas, sensoriais do sistema nervoso, memória, entre outros. Nesse sentido, recomendava, também, ser exercício do professor o reconhecimento dessas características nos discentes. E relutava:

É impossivel um mestre não saber reconhecer os sinais da fadiga na sua classe [...] basta reunir na sua lista: agitação, ticos ou cacoetes, trejeitos, bocejos, desatenção, distração, perturbações de memória ou da elocução, gagueira, etc. até mesmo modificações de côr da pele ou alteração do olhar. Indico ainda o acréscimo na lista dos atos impulsivos, as impulsões, a vontade de brincar, o brinquedo nas aulas, que seria então não uma indisciplina, mas um sinal de fadiga (PEIXOTO, 1925, p. 370).

Os saberes médicos indicavam a defesa do ensino o mais cedo possível, já que o turno da tarde, por si só, conduzia a um grau de fadiga mais acentuado que o da manhã e não devia ser aplicado senão com extrema prudência. Para o médico Farias de Vasconcelos "[...] é nas primeiras horas do dia que o calor tem menos intensidade, que o indivíduo se sente mais apto para o trabalho, por múltiplas condições physiológicas [...]" (DOENTEUR, 1928, p. 17). Foi pensando nessa proposta que o professor Abel da Silva, chefe da Instrução Pública no início da década de 1920, defendeu a abertura da escola às sete horas da manhã. Conforme o professor, essa ação representaria "[...] prejuízo para a família, mas vantagens ao magistério [...]" 
Para o cultivo da saúde: o programa de higiene nas escolas da Paraíba (191 3-1942)

(DOENTEUR, 1928, p. 17). Os pais deveriam acordar seus filhos às seis horas da manhã para as sete estarem prontos para o início das aulas. Nesse horário, de temperatura mais moderada ocorria a "[...] ativação da circulação, facilita a respiração, enriquece o sangue e é, sobretudo favorável ao trabalho mental da infância [...]" (MAROJA, 1913, p. 9). Ruiz Amado, em consonância com Abel da Silva, postulou que "[...] pela manhã, as creanças estão descansadas pelo somno da noite, que é o grande reparador da fadiga cerebral [...]" (MAROJA, 1913, p. 9). Ainda em defesa da execução das aulas no turno da manhã, o professor Abel da Silva escreveu: "[...] nas horas da tarde o calor mais intensivo alliado ao trabalho intelectual produz maior depressão orgânica, dispõe a preguiça e ao somno, há um exgotamento de energia, falta de attenção, indolência, enfim á indisposição do pequeno ser [...]" (SILVA, 1913, p. 9). Apesar das reclamações publicadas, durante as décadas seguintes, o horário escolar permaneceu inalterado das nove horas da manhã às quatorze horas da tarde.

Ainda sobre a fadiga, tão comum àqueles que trabalham e estudam, alguns médicos defendiam que o melhor antídoto para sua cura é o sono. $\bigcirc$ sanitarista Flávio Maroja, numa reportagem enviada A União em 22 de março 254 de 1925, garantiu a higiene do sono como medicação propícia ao cansaço. $\bigcirc$ bom sono

[...] regenera nossa atividade e renova automaticamente a iniciativa de nossas energias [...] elle modifica também os estados pathológycos do sistema nervoso e sensorial; verdadeiro agente curativo, banho sedativo para a atividade mórbida, elle suscita uma espécie de trabalho latente, que se produz pouco a pouco no subconsciente (DOENTEUR, 1925, p. 16).

Dessa forma, a privação do sono passou a ser considerada atividade anti-higiênica. Privar a criança do bom sono seria, na opinião do médico, causar doença mental e o agravo das dores físicas e morais. Portanto, prezar pela qualidade do sono deveria também ser bandeira levantada nas escolas através da matéria de higiene. $\bigcirc$ corpo repousado, após longas horas de sono, estava preparado para o bom rendimento da atividade intelectual. Todo cuidado era pouco diante da necessidade do repouso. Indicava-se evitar, à noite, alimentos e bebidas abundantes ou até mesmo estimulantes como café, 
cola ou chocolate, trabalho intelectual noturno e reuniões mundanas, todos considerados inimigos do sono higiênico.

Quando o tema era a educação da criança, o discurso médico enfatizava a necessidade da continuação da instrução saudável nas casas, a princípio, pelos filhos que, nos seus hábitos, apresentariam novos sentidos a seus familiares, ao mesmo tempo que os pais orientassem seus filhos para o respeito e uma boa educação. $O$ bom aluno, além de limpo, precisava ser educado.

A tarefa de educar "[...] requer um trabalho que dura vinte e quatro horas ao dia, durante cerca de vinte annos, sem descanso, nem férias [...]" (PATRI, 1943, p. 2). Essa receita orientava para a forte construção de um corpo saudável e educado, possível apenas por meio de uma "[...] instrução de saúde, sentido da rotina e do tempo, uma compreensão ampla da natureza do menino e alguns conhecimentos relacionados com o seu conhecimento e desenvolvimento [...]" (PATRI, 1943, p. 2). A ordem médica era enquadrar as crianças de acordo com os horários e programas que lhes assegurassem certa variedade de atividades, mas sempre no sentido educativo de moral e saúde. Todo o cuidado fazia-se necessário, pois da mesma forma "[...] que pais e professores olham para os seus pequenos para corrigílo-s, as crianças os observam, admirando o modêlo a seguir [...]" (LEÃO, 1930, s/p).

A boa postura, ou melhor, uma boa educação construída em parceria entre a família e a escola deveria evitar cenas como a vivenciada pela professora Hilda Avellar na Escola Mista de Cabedello, e, publicado no jornal A União. Vejamos a publicação:

Vamos, tire tudo isso daqui, imediatamente! Disse a professora a Carlito juntando com as mãos as casinhas que o garoto havia construído com seus blocos de madeira. Vinha meio zangada, com evidente mau-humor. Carlito e seus blocos de madeira fôram um ótimo motivo para a explosão. $\bigcirc$ garoto tinha apenas seis annos de idade e compreendeu perfeitamente o que acontecia. Sua raiva também teve uma explosão imediata. Gritou logo: - Não lhe quero mais bem. Nem um bocadinho! Queria que a Sra. não fôsse minha professora! (MAROJA, 1931 , s/p).

Mesmo expressando mau humor, a ordem da professora, em hipótese alguma, deveria ser contestada, muito menos respondida de forma 
"desaforada". $\bigcirc$ mesmo se aplicava em casa. Nesse sentido, respeito e organização se cruzavam na tarefa de formação da educação higiênica. $\bigcirc$ cuidado com o corpo e o respeito com os mais velhos precisavam ser ensinados como mandamentos de vida a serem seguidos, lição primeira, regra inquebrável. A narrativa acima apresentada mostra que a falta de respeito correspondia à falta de higiene, pois, além de espalhar os objetos pela sala de aula deixando-a desarrumada e fora de ordem, fez com que a professora e o aluno ficassem encolerados, ruborizados de raiva. Assim, as noções de educação do comportamento e do corpo deveriam mais do que nunca ser edificadas com base na cumplicidade entre ambas instituições. Flavio Maroja defendia que "[...] a salubridade precisa ser o meio, em que o menino tem de crescer e fazer-se homem [...]" (MAROJA, 1927, s/p), portanto, a casa paterna "[...] é o meio que o menino nunca de todo se subtrae [...]" (MAROJA, 1927, s/p). Noutras palavras, mesmo a escola conduzindo diretamente a criança ao seu aperfeiçoamento por meio da higiene, é preciso que o espaço que ela habite também seja higiênico, pois "[...] o temperamento moral da creança dependerá, sem contestação do ar, que ahi respirar [...]" (MAROJA, 1927, s/p).

$\bigcirc$ médico apropriou-se de metáforas para ensinar que a criança era 256 fruto do meio onde é criada: "[...] Cada planta prospera no seu meio [...]" (MAROJA, 1927, s/p); "[...] A laranjeira produz fructos suculentos nas vizinhanças dos rios [...]" (MAROJA, 1927, s/p). O mesmo acontece com o homem: "[...] não está insecto dessa lei geral. Se vive numa atmosphera viciada, contrai o contagio; mas se se desenvolve numa atmosfera pura o seu organismo será forte e resistente [...]" (MAROJA, 1927, s/p). Conforme os ensinamentos de Flávio Maroja, só a escola seria capaz de moldar os erros estruturais arquitetados em casa.

Nesse sentido, a família deveria ser orientada a seguir a cartilha da escola, especialmente no sentido de cumprir nos seus filhos as determinações higiênicas que recaiam sobre a casa, o corpo e a disciplina. Ensinamentos que poderiam andar de mãos dadas. Os pais precisavam observar para onde seus filhos iam, especialmente aqueles que já se direcionavam sozinhos às escolas, pois não era escasso o número de "[...] alumnos que apresentavam falsos motivos para deixar de ir a escola dias e dias [...]" (LEÃO, 1926, s/p) ou até mesmo, "[...] iludindo a vigilância paterna, vão perambular nas avenidas ou sentar-se nos bancos dos jardins, deixando desse modo que se passem as horas escolares para depois rumarem a residência [...]" (LEÃO, 1926, s/p). 
Ao tratar do tema, o chefe da Instrução Pública, Abel da Silva divulgava ser preciso "[...] incutir no espírito deles que as privações sofridas actualmente por não estarem a vagar pelas ruas, em virtude de ser necessário a sua presença na sala de aula $[\ldots]^{\prime \prime}$. Só assim, se tornariam cidadãos educados, moralmente formados e donos de uma saúde invejável, momento em que poderiam gozar dos bens físicos adquiridos ao longo do ensino primário e secundário. Guiava ainda os pais na missão de frequentar as escolas e travar diálogos com os professores "[...] indagando a assiduidade de seus filhos nos estabelecimentos de ensino onde estes aprendem para que possa collaborar com efficácia na educação daquelles que naturalmente se encontram sob seus cuidados [... $]^{\prime \prime}$ (LEÃO, 1926, s/p). E finalizava ditando o chefe da higiene, Flávio Maroja: "[...] A família e a escola, juntas farão mais e em menos tempo do que esta somente $[\ldots]^{\prime \prime}($ LEÃO, 1926, s/p).

diálogo em questão buscou assegurar, no começo do século XX, uma ação que priorizava a atenção da casa e da escola em torno das crianças. Ações como acordar cedo, tomar banho, escovar os dentes, vestir roupas limpas, ir à escola no horário certo deveriam ser asseguradas pelos pais; na escola, a tarefa de aprender hábitos sadios, permanecer limpo, sentar e andar corretamente, realizar as atividades mentais e da ginástica era dever dos professores. Para isso, a escola buscou criar uma série de normas que iam desde a simples fiscalização da higiene do corpo até a consulta médico-sanitária.

Embora pareça simples, a matéria de Higiene tratou de lançar suas raízes por todos os ambientes da escola. "Metia o bedelho" sobre corpos e posturas, formas de ensinar e aprender, normas e disciplinas. Vigilância parecia ser uma forte companheira na tarefa de educar para a saúde. As crianças eram inspecionadas já na entrada da escola pelo inspetor, diretor ou, até mesmo, pela professora. Unhas e mãos, roupas e sapatos, cabelos e orelhas, olhos e boca; nada escapava à lente dos "soldados da saúde". Na sala de aula, não era diferente, as determinações aumentavam, determinando inclusive a postura na hora de ler e escrever.

Enquanto na entrada dos alunos, nos corredores e no recreio, a fiscalização higiênica acontecia por vários funcionários, em sala de aula apenas o professor "[...] deve vigiar sobre todos esses meios e hábitos escolares [...]" (MAROJA, 1917, s/p), só assim seria possível "[...] completar a sua ação tutelar e pedagógica com todos os conselhos e advertências suasórias para corrigir más tendências e dar boa direção a espontaneidade infantil [...]" 
(PEIXOTO, 1925, p. 375). Porém, sempre de acordo com os ensinamentos médicos, que também fiscalizava. Todos os olhos estavam voltados para os corpos. Vigiavam se estavam limpos e puniam os sujos. Daí a necessidade constante da inspeção médica nas escolas, de forma individual nos alunos, nos professores principalmente para a prevenção de doenças transmissíveis.

Grupo Escolar Thomaz Mindêlo, localizado no centro da capital paraibana, gabava-se do fato de que "[...] todos os indivíduos destinados ao curso primário devem ser inicialmente examinados pelo médico escolar, não só para o conhecimento de suas condições pessoaes, como para prevenção de perigos possíveis para a coletividade escolar [...]" (MAROJA, 1924, s/p). $\bigcirc$ mesmo anúncio era comum a outras tantas escolas espalhadas pela Paraíba. Porém, o que mais chama atenção, daqueles que se debruçam sobre esses documentos, são as anotações médicas sobre o exame antropológico, ou melhor, exame físico, utilizado para "[...] conhecer o grau de desenvolvimento físico relativo á idade, [...] para conhecer a agudeza visual e auditiva necessária à prática escolar e para conhecer a regularidade de disposição de órgãos e exercícios das funções ósseas e muscular [...]" (PEIXOTO, 1925, p. 376). Para tanto, todos os dados eram recolhidos na observação pessoal e anotados 258 na ficha ou caderneta sanitária destinada a cada aluno. A primeira escola na Paraíba a adotar esse modelo de caderneta foi a Escola de Aprendizes Marinheiro, que reunia em um único lugar "[...] todos os exercícios mensaes do discípulo durante todo o seu curso primário [...]". As primeiras páginas dessas cadernetas

[...] são reservadas para observações feitas pelo professor no alumno; conterão a ficha escolar já instituída, o resumo do exame médico (medida do tórax, altura, sanidade, etc.), os testos de memória, do orgam visual, e outras anotações diversas [...] (MAROJA, 1914, s/p).

Afrânio Peixoto (1925, p. 316 ) defendeu essa união na perspectiva de observar corpo a corpo, aluno por aluno, a melhor forma de conduzir a higiene. Assim, a questão "[...] pedagógica, tanto como higienista é da competência do médico escolar, sem desinteressar a professora". Esses profissionais verificariam a capacidade mental dos alunos, o reconhecimento dos anormais, a distinção dos atrasados pedagogicamente, e dos "supernormais", apontariam os predispostos, os tarados, onânicos, enfermiços, os incompatíveis com 
a proposta da escola que, por sua vez, deveriam ser extirpados. O médico e o professor deviam saber atestar as condições hígidas ou normais de inteligência, e, principalmente, distinguir dos estados mórbidos, de idiotas, imbecilidade, debilidade mental, ou seja, todos aqueles considerados anormais.

Embora a atividade de diagnosticar as características fosse atribuída a professores e médicos, apenas este último poderia dar o veredito. Farias de Vasconcelos fez questão de advertir "[...] há muitos casos em que pela sua preparação thecnica que demandam, pelos instrumentos que requerem, o professor não poderá realizar; mas todas aquellas que o professor possa fazer, e o seu número é grande, deve fazê-las [...]" (MAROJA, 1913, p. 9), anotando-as nas cadernetas médico-pedagógicas ou mesmo nas fichas sanitárias. Porém, quando se tratava de documentos oficiais apresentados aos pais, a assinatura e a responsabilidade eram toda do médico.

Embora o número de publicações sobre formas de conduzir o ensino e os cuidados com a higiene nas escolas fosse crescente nos periódicos estaduais, nem sempre eram postas em prática. Algumas escolas, na década de 1920, pareciam "pardieiros", lugares onde "porcos e ratos desfilavam garbosamente". Focos de denúncias constantes que o porta voz do Estado - o jornal A União-acabava por desmentir. Em 1919, uma senhora de nome oculto denunciou a falta de higiene do Grupo Escolar Dr. Epitácio Pessoa, informando "[...] ao público que não funcionavam bem os aparelhos sanitários desse estabelecimento de ensino primário [...]" (MAROJA, 1919, s/p). Em resposta, o Sr. José Coelho e Eduardo Medeiros, respectivamente Inspetor-Geral do Ensino e Inspetor do Ensino Primário, afirmaram que "[...] não há razão numa varia publicada por um dos diários desta capital sobre a falta de hygiene no Grupo Escolar Epitácio Pessôa [...]" (MAROJA, 1919, s/p). Pediram para tranquilizar "[...] as famílias, pois o referido Grupo Escolar está perfeitamente hygienizado, não offerecendo o menor perigo a saúde das creanças que o frequentam [...]" (MAROJA, 1919, s/p). Fizeram, ainda, questão de divulgar que foram, pessoalmente, visitar a escola, onde encontraram os aparelhos em bom estado de funcionamento.

As denúncias passaram a ser recorrentes nos anos seguintes. Apesar do forte discurso médico, o investimento do governo estadual parecia ser bastante lento. Em 20 de março de 1927, foi publicada a denúncia de que "[...] apesar dos esforços, ainda continuamos sem a consignação de verba para a instalação da secção de higiene infantil nas escolas, que, este estado 
Para o cultivo da saúde: o programa de higiene nas escolas da Paraíba (191 3-1942)

aguarda a resolução humanitária [...]" (MACIEL, 1927, s/p). No mesmo mês, o Presidente do Estado da Paraíba, o Sr. João Suassuna, encaminhou à Assembleia Legislativa um ofício fazendo o seguinte apelo:

Aproveitando a oportunidade, lembro a v. exc. o serviço de hygiene infantil, fazendo-se mister, para a sua instalação methodica e regular, um additamento ao contracto existente com o Departamento Nacional de Saúde Pública, em que conste, conforme já foi combinado com a Directoria Geral de Saneamento Rural, uma contribuição a mais, de 50 contos de réis, dividida em partes eguais pelo Estado e pela União. [...] Mas a excassez de recursos com que tenho luctado, presentemente aggravada e sem modificação provável, impõe que adiemos ainda essa despeza, pois mesmo para o constracto assignado, não tem o tesouro contribuído com a regularidade do que depende em grande parte a efficiencia da repartição e dos trabalhos que a destina (PARAHYBA, 1927, s/p).

Na justificativa do Presidente do Estado ao prestar contas aos deputados ficam evidentes os motivos de não investir no Serviço de Hygiene Infantil. $\bigcirc$ repasse do governo federal não estava sendo feito. Assim, como medida pre260 ventiva, o presidente solicitou a aprovação de uma verba para o investimento na higiene infantil, que, apesar "de sua boa vontade", não era possível dispor dos minguados valores destinados à educação. Para isso, foi sugerido que se retirasse o valor de 50 contos de réis dedicados ao Serviço de Saneamento Rural para investir nos cuidados à infância. Os valores seriam aplicados na compra de instrumentos e mobília para as escolas que careciam de aparelhos higiênicos, na reforma de espaços ainda considerados insalubres e na aplicação em outras instituições protetoras da infância, a exemplo dos hospitais.

Eram constantes as cartas que denunciavam a necessidade de uma rápida educação higiênica nas escolas em todos os municípios do estado que, segundo Acácio Pires, estava recheado de Jecas, vivendo em palhoças feitas com palhas de coqueiro, sob a total ausência de fossa e higiene. A única forma encontrada pelo médico foi alertar o Chefe do Saneamento em nível federal, Belisário Penna, alegando em sua carta que a educação sanitária "[...] é a única coisa de que ainda não pudemos cuidar a despeito de considerá-la da maior relevância [assim] a educação sanitária nas escolas, subsistindo, parece-me de grande utilidade [...]" (PIRES, 1921 , s/p). Ademais, falou da dificuldade de educar os jecas que "[...] por falta de sciência se 
atocham de preconceito, que são a tiranice que não deixa lugar para a boa semente medrar $[\ldots]^{\prime \prime}$ (PIRES, 1921, s/p). Na tarefa de medicar os adultos e educar as crianças, a propaganda sanitária tinha uma grande relevância, para tanto, suplicava-se o pedido de que "[...] o senhor [Belisário Penna] nos mande quadros muraes, filmes, folhetos, etc., que representem elementos da convicção de mais alto valor [...]" (PIRES, 1921, s/p).

Noutra carta enviada a Belisário Penna em 4 de setembro de 1931 , Aprígio Gonzaga afirmou que não se poderia fazer "[...] escolas de fachadas, inúteis socialmente falando, e deixar analfabeto o matuto, o caiçara, o caipira, o mané chique-chique adorando um boi, como nas terras do Padre Cícero se fazia [...]" (PENNA, 1931, s/p). Era dever dos médicos pregar e infundir os preceitos de higiene, dar "[...] as mãos ao que divulga a cartilha e espalha escolas primárias [...]" (PENNA, 1931 , s/p). Dessa forma, "a moleza de lesma"b do povo deveria ser combatida como nos ensinamentos higiênicos postulados na escola.

Em 26 de junho de 1934, o jornal A Imprensa, estampou, em suas páginas, a denúncia de que as inspeções médico-escolares estavam entregues às enfermeiras, especialmente nos municípios do interior do estado. Logo em seguida, A União respondeu à denúncia, afirmando que o fato procedia devido à ausência de profissionais médicos para atender a todas as cidades, ao rápido crescimento da população que prendia por mais tempo os médicos nos consultórios e hospitais e que era preciso combater a mortandade de crianças de forma incansável. Destacou, ainda, que "[...] tudo isso será resolvido logo que as condições financeiras do erário público permitam que se possam assumir, convenientemente, responsabilidades dessa ordem [...]" (MACIEL, 1934, s/p); e que investiria pesado em formação higiênica para melhor orientar os cidadãos no trato com as crianças desde os primeiros meses de sua existência, passando por toda a infância e adolescência e chegando a vida adulta. Nesse sentido, a melhor forma de combater a falta de higiene, as doenças e as torpezas seria investir, cada vez mais, na educação da saúde efetivada nas escolas e na matéria de higiene. Era preciso, portanto, estar atento para o conteúdo ensinado nessa cadeira, investindo nos encontros pedagógicos e na formação de professores. 


\section{Brincar de aprender Higiene: o Programa de Educação da Saúde}

Entre as escolas que participaram da Semana Pedagógica, apenas - Grupo Escolar Antônio Pessoa e o Grupo Escolar Isabel Maria das Neves expuseram jogos na temática em análise. $O$ primeiro intitulou seus jogos de "Geometria e Hygiene" e "Hygiene e português". Nesses jogos, tanto as formas geométricas quanto as letras do alfabeto eram associados diretamente à saúde. Em "Geometria e Hygiene", o jogo tinha o formato de um quebra-cabeça, onde as peças em tamanhos "[...] desinguaes eram empregados para a percepção das formas e do corpo, attinando para hygiene do corpo [... ]" (MELLO, 1936, p. 94). A união de três peças do quebra-cabeça equivalia a uma parte do corpo com sua respectiva forma de limpar. Já em "Hygiene e Português", as professoras apresentaram o alfabeto da saúde em que todas as letras obedecendo à sequência do alfabeto correspondiam a uma norma higiênica aprendida na escola e efetivada em casa. A professora Maria Camerina Bezerra Cavalcanti alegou que seguir a ordem do alfabeto da saúde era o princípio básico para as normas de higiene diária, portanto, segundo ela, a regra da letra $A$ deveria ser a primeira tarefa do dia, seguido pela $B, C, D \ldots$

262 Segundo a professora, a ordem não deveria ser alterada.

○ Grupo Escolar Isabel Maria das Neves cuidou de apresentar "Sete jogos para educação dos sentidos", na qual o sétimo, intitulado "Educação do sentido básico" versava sobre os preceitos de higiene. Em formato de dominó, a imagem do corpo deveria ser associada à prática de saúde correta. A professora Marluce Barros, responsável pela apresentação do jogo aplicado na matéria de Higiene do primeiro ano do Ensino Primário, alegou que "[...] quanto maior e mais côr possuir as peças do dominó mais o aluno entenderá [...]" (MELLO, 1936, p. 94), consequentemente, tornar-se-á mais hígido. Os jogos apresentados procuravam imprimir um ar de pedagógico e, ao mesmo tempo, ser atrativo à criança, chamando sua atenção, e, por sua vez, disciplinando para a educação da saúde.

Essas ações faziam parte da proposta pedagógica exigida pelo programa de ensino, criado para as escolas durante a década de 1930, além de estar em acordo com a reorganização do Ensino Primário da Paraíba ocorrida em 1935, que priorizava, entre outros pontos importantes, a "[...] multiplicação das escolas e a difusão do ensino pelo interior do estado, a construção de edifícios escolares higiênicos nas cidades, villas e povoações e o novo plano da 
hygiene, educação physica[...]" (DUARTE, 1936, p. 20). Noutro documento, publicado em 1942, foi decretada a instauração obrigatória do Programa de Educação de Saúde definindo-o como a "[...] soma de experiências, na escola ou em qualquer lugar, influenciando favoravelmente hábitos, atitudes e conhecimentos relativos á saúde do indivíduo, da coletividade e da raça [...]" (MELLO, 1942, p. 37). Assim, o dever do professor seria velar pelo desenvolvimento natural da criança do ponto de vista da saúde física, mental, social e moral. Ao narrar sua finalidade, o decreto afirmava "[...] assegurar ás crianças uma vida tão sadia quanto for humanamente possível, inculcar-thes hábitos e orientá-las na aquisição dos conhecimentos práticos essenciais ao cultivo da saúde [...]" (MELLO, 1942, p. 37). Assim, com o término do curso primário, foi possível formar, nas crianças, "uma consciência bem viva de saúde" capazes por "[...] cooperar inteligentemente no cultivo de sua própria saúde e na defesa da saúde da coletividade [...]" (MELLO, 1942, p. 37).

Alguns anos antes, um programa de rádio chamado "Higiene na Rádio Tupi" reivindicava a necessidade do bom ensino de higiene nas escolas do interior da Paraíba, visto que a principal alegação era de que essa educação dos sentidos estava restrita à capital e a algumas poucas cidades consideradas importantes economicamente para a Paraíba, como Campina Grande, Cajazeiras, Guarabira, Areia e Sousa. A palestra intitulada "A cadeira de higiene" defendia a ausência da matéria nessas escolas como uma atitude arbitrária, da mais "[...] completa ignorância das noções fundamentais de Higiene, quer às destinadas a defender o indivíduo, quer a destinada à preservação da sociedade contra inúmeras doenças [...]" (GASPARINI, 1939, p. 49). Criticava o fato da reforma no ensino de 1935 por haver fixado

[...] grande número de horas para o estudo fastigioso de línguas defuntas, como o grego e o latim, em prejuízo as noções rudimentares das ciências físicas e naturais, entre as quais figuravam, embora escassamente, algumas lições de higiene (GASPARINI, 1939, p. $50)$.

Defendia, ainda, que as noções de higiene deveriam ser recorrência nos níveis primário e secundário para que a ciência da saúde fosse mais bem "[...] compreendida no seu mais elevado e útil objetivo de protetora da saúde individual e coletiva [...]" (GASPARINI, 1939, p. 51). 
Para o cultivo da saúde: o programa de higiene nas escolas da Paraíba (191 3-1942)

Noutra palestra ecoada pelas ondas sonoras da Rádio Tupí, a defesa dos saberes médicos sobre a higiene na escola se justificava pelo fato de vivermos num país onde

[... ] o número de doenças evitáveis e curáveis ainda é tão avultado, onde é preciso dar a maior divulgação aos preceitos higiênicos, as regras de profilaxia geral e específica das doenças, responsáveis em parte, pelo seu lento progresso, é simplesmente um crime desprezar tão importante matéria. A juventude brasileira deve conhecer de perto os magnos problemas sanitários de cuja solução depende a grandeza da nação (GASPARINI, 1939, p. 50).

Em sua fala de abertura na formação higiênica de professores, Flávio Maroja alegou que é "[...] na escola que se acende no coração dos moços, os santos entusiasmos pelas nobres campanhas em prol da saúde do povo [...]" (MAROJA, 1937, s/p), especialmente como forma de evitar os perigos de meio ambiente, propício ao desenvolvimento de germes de doenças, quando não há saneamento, além de prezar pelo conhecimento da higiene individual, habituando, desde a infância, a zelar constantemente pela própria saúde, fonte de força e alegria. Dessa forma, os professores, ao repassar os ensinamentos para os alunos, também atribuia-thes a responsabilidade do cuidado com seu corpo, considerado "[...] um centro de irradiação de ensinamentos e modificador da mentalidade retrógrada de seus pais e familiares [...]" (GASPARINI, 1939, p. 50).

Tudo deveria conspirar a favor: o prédio e suas dependências, o mobiliário, o material, o aparelhamento escolares precisam satisfazer os requisitos de higiene; perfeitos deveriam ser o fornecimento de água e as instalações sanitárias, os lavatórios e banheiros aparelhados e funcionando convenientemente sem falta e sem desperdício de água, com toalhas individuais ou sem toalhas, com papel higiênico sempre jogado dentro da latrina, balança e craveira. $\bigcirc$ regulamento prezava pela organização do trabalho educativo visando, em primeiro lugar, à saúde das crianças, lembrando sempre que "[...] um programa não poderá ser considerado higiênico si exigir mais trabalho do que deverem as crianças fazer, sobrecarregando-as física ou mentalmente [...]" (MELLO, 1942, p. 38). Todo o trabalho pedagógico e higiênico deveria ser dosado entre os trabalhos, a recreação e o repouso; observando ainda os cuidados na sala de aula com as 
[...] atitudes corretas sem esforço do corpo, á visão, á audição

[...] é importante que o trabalho seja convenientemente escolhido e dosado de modo a adaptar-se á capacidade da criança, a seu desenvolvimento físico quanto mental, a sua saúde e a suas forças (MELLO, 1942, p. 38).

O Programa de Educação de Saúde, instituído na Paraíba, indicava a sempre necessária influência dos professores e funcionários, como requisito básico do programa escolar, atuando, sadiamente, sobre a personalidade da criança, principalmente pelo seu exemplo de hábitos sadios. Na reportagem d'A União de 9 de junho de 1935, exigia-se que assim como os alunos, "[...] o professor deve também submeter-se anualmente, a um exame médico para verificação de sua higidez normal e á vacinação anti tífica e disentérica - apenas quando as condições locais a isso obrigarem [...]", além de apresentar perfeita dentadura: forte e branca. $\bigcirc$ Programa ressaltava que as práticas saudáveis fossem exigidas desde os funcionários mais subalternos até mesmo a colaboração do lar e da comunidade.

Observando programa escolar da matéria de Higiene, deve-se ter em mente que as que mais se destacam repetidas vezes, são aquelas que inferem sobre cuidados com o corpo e com a casa, sobre nutrição e puericultura. Ao traçar um plano de ação a ser desenvolvido nas escolas da Paraíba e inseridos no programa de ensino, o Departamento de Educação determinou a execução dos seguintes termos:

a) formar nas crianças hábitos físicos e mentais essenciais á saúde; b) orientá-las na aquisição dos conhecimentos práticos, especialmente de biologia e higiene, necessários á racionalização dos hábitos sadios e indispensáveis ao cultivo da saúde; c) desenvolver nas crianças os ideais e as atitudes mentais convenientes ao cultivo da saúde individual e á beleza da saúde coletiva; d) crear e estimular o interesse da família e da comunidade pelo trabalho que a escola faz em prol da saúde das crianças (MELLO, 1942, p. 40).

O programa escolar priorizava a base de toda a educação da saúde pautada na proliferação dos hábitos pessoais higiênicos do bem-viver, dos cuidados com a alimentação que se ingeria, da limpeza do vestuário, do bom sono, da prática de exercícios físicos, da conduta mental, emotiva e social e da própria segurança pessoal. A Revista do Ensino, publicada no 
Para o cultivo da saúde: o programa de higiene nas escolas da Paraíba (191 3-1942)

primeiro semestre de 1942, ditou as novas normas para o ensino primário de higiene que deveriam ser adquiridas pelas crianças como princípio de saúde: "a) Higiene corporal, alimentar e do vestuário nas diferentes idades; b) Saneamento ou problemas de saúde locais; c) Biologia; d) Modo de procurar e utilizar o Serviço de Saúde e o conselho médico; el Cuidado as crianças e aos doentes".

A professora do primeiro ano do ensino primário do Colégio Nossa Senhora das Neves registrou, em 15 de maio de 1940, no espaço reservado às anotações de aula da caderneta anual, que, durante a aula de Higiene, o tema debatido fora o "asseio da pele". Ela se valeu dos ensinamentos do médico Carlos Sá para explicar que a "[...] função da pele é proteger o corpo, lugar de máxima sensibilidade, de excreção do suor e de contato com o meio externo [...]" (SÁ, 1938, s/p). Portanto, é um órgão que exige bastante cuidado, a começar pelo seu asseio "que elimina o sujo, que se compõe de célular epiteliais descamadas, do desgaste do vestuário, das poeiras domiciliares urbanas e de micróbios" (SÁ, 1938, p. 120). O asseio deveria ser feito sempre com água corrente, ou com "[...] loções alcoolicas e crêmes ligeiramente oleosos, que, pela ação dissolvente de suas subtancias constitutivas, 266 servem a limpeza do rosto, das mãos, da cabeça e do corpo [...]" (SÁ, 1938, $\mathrm{s} / \mathrm{p})$. $\bigcirc$ mesmo valia para os banhos, utilizando sempre "água, lavagens a abluções". Eram citados como espécie de "[...] imersão, gastando-se para elles, nas banheiras usuaes, cerca de duzentos litros de água, ou de aspersão, de chuveiro, que exige apenas de trinta a cinquenta litros [...]" (SÁ, 1938, $\mathrm{s} / \mathrm{p}$ ). $\bigcirc$ banho poderia ser realizado com água fria, morna ou quente, mas sempre com duração de, no máximo, cinco minutos.

A orientação do médico para a professora foi chamar a atenção para a temperatura, visto que

[...] banho frio rouba calor, pelo que, os vasos sanguíneos periféricos se contraem, a pele empalidece e se arrepia, muda a reação orgânica; [iá] os banhos mornos facilmente se estabelece o equilíbrio térmico entre a água e o corpo, fazendo com que a criança passe mais tempo no banho, fazendo-se melhor o asseio. Nos banhos quentes, a primeira reação do corpo é para aumentar a perda de calor, agravada pela temperatura da água, ocorre o aquecimento da pele podendo causar graves danos a saúde (SÁ, 1939, p. 1211 . 
No caso da higiene de partes do corpo, recomendavam-se as abluções ou banhos parciais, especialmente para o rosto, as mãos e os pés. $\bigcirc$ mesmo se aplicava aos cabelos que deveriam ser lavados com shampoo ou sabonete de coco, conforme a produção de glândulas sebáceas e no combate à caspa. No caso de cabelos gordurosos, indicavam-se as loções oleosas com ou sem quina, óleo de rícino. O cabelo deveria ser cortado, no caso dos meninos a cada três semanas, e, para as meninas, aparavam-se as pontas.

Quanto ao rosto, aconselhava lavar com água fria especialmente ao acordar, deitar ou voltar ao trabalho, utilizando sabonete de glicerina; as mãos "[...] cujo corte de unhas se fará uma a duas vezes na semana, devem ser lavadas com sabonetes várias vezes por dia: de manhã, antes de qualquer refeição, depois de ir ao W.c., ao voltar para casa, ao deitar-se [...]" (SÁ, 1939, p. 122). Flávio Maroja alegava, desde 1920, o cuidado com as mãos, "[...] recomendando a supressão do aperto de mãos, pois o cumprimento das mãos seria um forte meio de transmissão de doenças, como gripe, febres, etc" (SOARES JÚNIOR, 201 1, p. 98). A transpiração das mãos era uma exigência do corpo de uma constante higienização dessas partes, pois "[...] estes suores constituem um inconveniente que pode advir no verão de uma verdadeira enfermidade [...]" (SÁ, 1938, s/p). Mãos suadas causavam, nas pessoas, uma impressão desagradável, e, se não realizada a limpeza, passam a exalar um odor azedo.

"A mão é o gesto, o gesto é a palavra visível, a palavra visível é a alma, a alma é o homem... e a alma do homem está nas mãos [...]". Assim, Flávio Maroja (1921 , s/p) abria a palestra intitulada "As mãos e a higiene" publicada no jornal A União em 22 de fevereiro de 1938. $\bigcirc$ médico paraibano Flávio Maroja, em um de seus discursos, que, a meu ver, apresentava um tom moralista sobre o beijo, em suas palavras, considerado maldito, também dedicou sua atenção aos cuidados com as mãos, alegando que essa parte do corpo "[...] bem merecem um capítulo especial em Higiene, dada sua importância, como instrumentos de progresso da humanidade [...]" (MAROJA, 1921, $\mathrm{s} / \mathrm{p}$ ). Por serem as mãos instrumento tão necessário ao homem, requeria toda a atenção possível, pois, da mesma forma que a mão alimenta, afaga, acena, aplaude, também traz o contágio de doenças ao corpo, entra primeiro em contato com o sujo. Portanto, convém "[...] saber que elas, por ignorância ou descuido, podem ser propagadoras de graves moléstias [...]" (GASPARINI, 1939, p. 83). Eram necessários sérios cuidados com as mãos. Os "chavões" 
Para o cultivo da saúde: o programa de higiene nas escolas da Paraíba (191 3-1942)

da época faziam questão de ressaltar que a maioria das doenças costumavam chamar de "doença de mãos sujas", portadora ainda das "unhas de luto" tão repugnantes e perigosas.

As unhas dos pés precisavam também ser aparadas semanalmente, exigindo cuidados dobrados de asseio com água e sabão, não apenas no banho, mas também antes de se deitar, especialmente as crianças. $\bigcirc$ asseio dos pés tinha a função de combater micoses, vermes, frieiras, suores nos pés e chulé; portanto, a ordem era: lavar bem e enxugar bastante!

Os livros utilizados pelas professoras na matéria de higiene - A fada Higia $^{7}$ - vinham acompanhados de orientações para os cuidados com partes específicas do corpo: cuidados com as axilas evitando mau cheiro, a higiene das orelhas para não criar sulcos repugnantes, utilizando sempre "[...] água morna no pavilhão das orelhas e carbonato de sódio para dissolver o cerúmen [...]" (MAROJA, 1927, s/p); destacava a limpeza da boca não admitindo para as crianças o uso de batons que "[...] poderiam causar irritações desagradáveis de difíceis tratamento [...]" (KEHL, 1927, s/p); da língua realizando "[...] bochechos com água fria, uso de dentifrícios alcalinos e saponáceos, líquidos ou em pasta [...]" (KEHL, 1927, s/p) evitando o acúmulo de bactérias, 268 e, o trato com os dentes que exigiam cuidados especiais, por "[...] sua importância na digestão e pela sua vulnerabilidade a lesões e infecções [...]" (SÁ, 1939, p. 124), lembrava ainda da necessidade de ingerir alimentos ricos em cálcio, como leite e queijo para prevenir ou diminuir as cáries. A higienização dos dentes deveria ocorrer "[...] duas a três vezes por dia com escova pequena e pelo não muito duro, fricção circular da raiz para coroa, dentifrício pastoso e alcalino, e, à noite, fio encerado, seguido de bochecho de água fria ou morna [...]" (MAROJA, 1931 , s/p); cuidados no trato com a pele do rosto, especialmente quando começa a aparecer erupções do rosto, espinhas e cravos, ou, até mesmo, sardas e doenças da pelo, sendo necessária a apresentação do aluno ao médico escolar, responsável por realizar exame criterioso. As normas ainda contemplavam os cuidados com o olfato onde, nas fossas nasais, o asseio se

[...] fará com água morna, simples, salgada ou boricada, a proteção contra poeiras exige às vezes óleos ligeiramente antissépticos, além de evitar o arranchamento de pêlos, o traumatismo de espinhas que podem provocar congestões intensas ou infecções graves (SÁ, 1939, p. 124). 
A água fria também era indicada para lavar bem os olhos, retirando as secreções que escorrem por eles. Após a concretização desses procedimentos higiênicos, o asseio do corpo deveria ser assegurado por meio de água corrente e em abundância. A pele limpa "[...] acentua os perfis, matiza os comentários, às vezes estendendo-se até mesmo as atitudes e aos comportamentos [...]" (VIGARELLO, 1996, p. 89). A higienização se ampliou para todas as partes do corpo, não só rosto e mãos, mas também pés, axilas, órgãos sexuais, cabelos, orelhas, pernas, etc., os vários pontos focalizados do corpo se correspondem. Se não são cuidados, disseminam maus odores. Por isso, a lavagem da pele era considerada imprescindível, pois, conforme o discurso médico da época, muitas pessoas esfregam com as mãos, esse processo nada valia a não ser para chamar o sangue, mas não limpava o redor dos poros, daí ser de toda conveniência o emprego de uma esponja ou toalha com felpos finos.

As normas de higiene versavam ainda sobre a segunda pele, assunto tão recorrente no programa escolar. $\bigcirc$ vestuário foi apresentado pela formação médica como portadora da função de proteção e de regulação térmica, exigindo asseio. Segundo Carlos Sá (1939), o vestuário protege contra agentes mecânicos, por meio de sapatos e capacetes; agentes físicos, pelo uso de cores claras no verão e escuras no inverno; químicos com luvas e máscaras; e biológicos as luvas contra os micróbios, as botas contra as serpentes, os sapatos na prevenção da ancilostomose.

Seja como for, o que estava em pauta eram as formas de higienizar os corpos das crianças. Hábitos que deveriam ser ensinados e defendidos a todo custo em sala de aula. Esses documentos publicados nos jornais e distribuídos aos professores, são, a nosso ver, manuais de civilidade, espaços de divulgação de normas disciplinares, regras higiênicas que visavam moldar os corpos, transformá-los em símbolos de saúde, e, representação daquilo que era considerado moderno.

\section{Considerações finais}

No nosso trabalho, a educação da saúde e educação da higiene revelou-se por meio das orientações médico-pedagógicas, difundidas pelas 
Revistas e Jornais em circulação na Paraíba nas primeiras décadas do século $X X$.

A higiene era assunto da ordem do dia. A publicação da Constituição de 1937 reafirmou a obrigatoriedade do ensino de Higiene em todo o país, não apenas no Ensino Primário, mas também no Secundário e nos Ginásios. De acordo com Savino Gasparini (1939), a criação da cadeira de Higiene responsável por disciplinar o Brasil teve como consequência imediata a publicação em larga escala, de obras didáticas que foram espalhadas em todo o território nacional, além da realização de conferências, palestras e exposições de higiene. Essas realizações asseguradas por lei foram divulgadas como o "[...] maior serviço prestado à propaganda e educação sanitária, destinada a mostrar a todo cidadão o valor da saúde, base da felicidade individual e coletiva e condição precípua de progresso da Pátria [...]" (GASPARINI, 1939, p. 531. Os discursos médicos produzidos miravam-se para as escolas, seus prédios, suas normas, os corpos dos alunos, os conteúdos. Orientações foram constantemente produzidas por médicos de renome como Belisário Penna, Renato Kehl, Afrânio Peixoto, Flávio Maroja. Livros didáticos que deveriam ser lidos, relidos e analisados em sala de aula.

270 Grande parte dessa produção também versava sobre a filha da higiene: a educação física. Modelar o corpo não significava apenas limpá-lo, mas também torná-lo forte, resistente, capaz de trabalhar incansavelmente. $\bigcirc$ corpo forte fisicamente era considerado sinônimo de saúde, fonte de vida. As atividades de ginástica, embora realizadas na matéria de Educação Física, surgiram, inicialmente, atreladas aos preceitos de cuidados com o corpo, portanto, da higiene. Dessa forma, a introdução da matéria de Educação Física, nas escolas da Paraíba, foi fruto da divulgação dos princípios higiênicos. Para a ordem médica em voga, higienizar também era construir um corpo forte, rijo e belo. Normalizar os corpos das crianças nas escolas parecia ser norma primeira do Programa de Educação da Saúde.

\section{Notas}

1 As Revistas do Ensino, circularam na Paraíba entre os anos de 1930 e 1942. Incumbiram-se da missão de fazer circular um saber próprio aos docentes. Esse periódico revestiu-se do discurso de uma educação capaz de formar um cidadão saudável e defensor de sua pátria e em consonância com a ideologia da Era Vargas (Cf. SOARES JUNIOR, 2015, p. 24). 
2 A União, o periódico mais antigo que ainda circula na Paraíba foi fundado a 02 de fevereiro de 1893, como órgão divulgador do Partido Republicano, apoiando a gestão do seu fundador, o então presidente Álvaro Lopes Machado, é o terceiro jornal mais antigo em circulação no Brasil. Ver: Paraíba, imprensa e vida (ARAÚJO, 1983).

3 Em Os anormais (FOUCAULT, 2010), o termo normal ganha outros sentidos. O autor faz questão de ressaltar que derivam dessa palavra os termos normatização e normalização. $\bigcirc$ primeiro são aqueles envolvidos com o estabelecimento das normas, aqueles que a criam (políticos e o Estado), já o termo normalização é composto por aqueles que buscam colocar todos sob uma norma já (médicos, professores).

4 antigo Instituto Pedagógico passa a se chamar na década de 1940 de Ginásio Alfredo Dantas.

5 Oscar de Castro defendia que a primeira infância carecia de todo o cuidado, especialmente no setor fisiopatológico do aparelho digestivo. Durante a segunda infância e na adolescência já absorvidas pela instrução primária e secundária, pela atenção dos médicos e professores, bem como do valor educativo do programa de ensino, aprenderiam os cuidados higiênicos com o corpo e a mente.

$6 \bigcirc$ médico Acácio Pires afirmou em carta enviada a Belisário Penna em 9 de maio de 1921 que "o povo é de uma moleza de lesma", no sentido de que parecia não haver pressa para se inculcar os novos preceitos normativos de higiene.

7 A fada Higia de autoria do médico eugenista Renato Kehl, foi o livro didático adotado pelas escolas da Paraíba nas décadas de 1930 e 1940. A primeira edição data de 1925 e foi publicada pela Livraria Francisco Alves.

\section{Referências}

ARAÚJO, Fátima. Paraíba, imprensa e vida. João Pessoa: A União, 1983.

PIRES, Acácio. [Carta] 15 set. 1921, João Pessoa [para] Belisário Penna, Rio de Janeiro. (Arquivo da Fiocruz, Rio de Janeiro, 15 set. 1921 - datilografado).

GONZAGA, Aprígio. [Carta] 4 set. 1931, João Pessoa [para] Belisário Penna, Rio de Janeiro. (Arquivo da Fiocruz, Rio de Janeiro, 4 set. 1931 - datilografado).

COLLEGIO NOSSA SENHORA DAS NEVES. A Imprensa, João Pessoa, p. 12, 29 jan. 1927.

DIRECTORIA DE HYGIENE. A União, João Pessoa, s/p., 22 jan. 1913.

DOENTEUR. A hygiene mental do neurathenico. A União, João Pessoa, p. 16, 25 jan. 1925. 
Um capítulo de hygiene intelectual do trabalho escolar. A União, João Pessoa, p. 10, 13 mar. 1928.

DUARTE, Débora. A reorganização do Ensino Primário. Revista do Ensino, João Pessoa, n. 12, p. 20-35, jan./jun. 1936.

FOUCAULT, Michel. Os anormais. Petrópolis: Vozes, 2010.

GASPARINI, Savino. Palestras de higiene na Rádio Tupí. Rio de Janeiro: Ministério da Educação e Saúde, 1939.

KEHL, Renato. Higiene infantil. A União, João Pessoa, s/p., 31 jul. 1927.

LEÃO, Carneiro. A família e a escola. A União, João Pessoa, s/p., 28 fev. 1926.

A criança escolar. A Imprensa, João Pessoa, s/p., 23 out. 1930.

MACIEL, J. Hygiene infantil. A União, João Pessoa, s/p., 20 mar. 1927.

Hygiene. A União, João Pessoa, s/p., 28 jun. 1934.

MAROJA, Flávio. Hygiene escolar. A União, João Pessoa, p. 9, 24 nov. 1913.

272 - Varíola. A União, João Pessoa, s/p., 2 mar. 1914.

Hygiene. A União, João Pessoa, s/p., 26 jan. 1917

Hygiene escolar. A Imprensa, João Pessoa, s/p., 2 set. 1919.

Sentença médica. A União, João Pessoa, s/p., 13 ago. 1921.

Hygiene nos grupos escolares. A União, João Pessoa, s/p., 12 jan. 1924.

. Os hábitos. A União, João Pessoa, s/p., 28 jun. 1927.

A educação do lar. A Imprensa, João Pessoa, s/p., 13 jul. 1927.

. Educação e propaganda sanitária. A União, João Pessoa, s/p., 19 set. 1931.

. Vida escolar. A União, João Pessoa, s/p., 7 mai. 1937.

MELLO, José Baptista. Programma de ensino. Revista do Ensino, João Pessoa, n. 14, p. 95-1 16, jul./dez. 1936.

Educação da saúde (orientação). Revista do Ensino, João Pessoa, n. 17, p. 36-39, jul./dez. 1942. 
PARAHYBA. A União, João Pessoa, s/p, 10 set. 1927.

PATRI, Ângelo. Problemas na educação dos filhos. A União, João Pessoa, p. 2, 01 abr. 1943.

PEIXOTO, Afrânio. Noções de higiene. Rio de Janeiro: Livraria Francisco Alves, 1925.

REFORMA DO ENSINO. A União, João Pessoa, p. 13, 11 dez. 1918.

SÁ, Carlos. Vida escolar higiênica. A União, João Pessoa, s/p., 22 abr. 1938.

1944.

Higiene e educação da saúde. Rio de Janeiro: Ministério da Educação e Saúde,

SILVA, Abel. Higiene dos escolares. A União, João Pessoa, p. 9, 25 mar. 1913.

SILVA, Pierre Normando Gomes da; CAVALCANTI, Kátia Brandão. Da cultura corporal a corporeidade: por uma inversão epistêmica na educação física. Revista Educação em Questão, Natal, v. 19, n. 5, p. 69-87, jan./abr. 2004.

SOARES JR, Azemar dos Santos. Corpos hígidos: o limpo e o sujo na Paraíba (1 91 2-1924). 2011 . 203f. Dissertação (Mestrado em História) - Programa de Pós-Graduação em História, Universidade Federal da Paraíba, 2011.

Physicamente vigorosos: medicalização escolar e modelação de corpos na Paraíba (1913-1942). 2015. 270f. Tese (Doutorado em Educação) - Programa de Pós-Graduação em Educação, Universidade Federal da Paraíba.

VACCINA ESCOLAR. A União, João Pessoa, s/p., 2 dez. 1939.

VAGO, Tarcísio Mauro. Uma verdadeira revolução dos costumes: educação de corpos infantis na reforma do ensino de 1906 em Minas Gerais. In: FARIA FILHO, Luciano Mendes; FERNANDES, Rogério; LOPES, Alberto. Para a compreensão histórica da infância. Belo Horizonte: Autêntica, 2007.

VIDA ESCOLAR. A União, João Pessoa, p. 5, 26 ago. 1926.

VIGARELLO, Georges. O limpo e o sujo. Uma história da higiene corporal. São Paulo: Martins Fontes, 1996.

Prof. Dr. Azemar dos Santos Soares Júnior Universidade Federal do Rio Grande do Norte Departamento de Práticas Educacionais de Currículo 
Artigo

Para o cultivo da saúde: o programa de higiene nas escolas da Paraíba (1913-1942)

Grupo de Pesquisa História da Educação no Nordeste Oitocentista | UFPB - CNPq E-mail | azemarsoares@hotmail.com

Profa. Dra.Cláudia Engler Cury Universidade Federal da Paraíba

Departamento de História

Programa de Pós-Graduação em Educação Líder do Grupo História da Educação no Nordeste Oitocentista | UFPB - CNPq E-mail | claudiaenglercury73@gmail.com

Recebido 31 ago. 2016 Aceito $1^{\circ}$ nov. 2016 